\title{
O aluno com deficiência na EJA: reflexões sobre o atendimento educacional especializado a partir do relato de uma professora da educação especial
}

\author{
Juliane Ap. de Paula Perez Campos* \\ Márcia Duarte**
}

\section{Resumo}

O presente texto tem por objetivo mostrar como se constitui a parceria entre o Atendimento Educacional Especializado (AEE) e a Educação de Jovens e Adultos (EJA) em uma escola da rede municipal de uma cidade de médio porte da região central do estado de São Paulo. Trata-se de um estudo que teve como referência metodológica a pesquisa exploratória, a partir da perspectiva do estudo de caso. O estudo foi realizado em uma escola municipal de ensino fundamental que possuía alunos com deficiência matriculados na modalidade de Educação de Jovens e Adultos. A coleta dos dados se deu por meio de entrevista com roteiro semiestruturado, tendo como foco o Atendimento Educacional Especializado junto aos alunos com deficiência da Educação de Jovens e Adultos. Os resultados, ainda que exploratórios, evidenciaram que a maioria dos alunos com deficiência da EJA tinha deficiência intelectual, eram trabalhadores e não frequentavam o $\mathrm{AEE}$, uma vez que os professores da EJA não apresentavam dificuldades no trabalho com estes alunos. É preciso novos estudos que contemplem ações necessárias à efetiva parceria entre a EJA e a Educação Especial.

Palavras-chave: Educação especial. Educação de Jovens e Adultos. Atendimento educacional especializado.

\section{Students with disabilities in adult education: reflections on the specialized educational services from the report of a special education teacher}

\begin{abstract}
The goal on this present study is to demonstrate the partnership between specialized educational services and Education of young and adults. This partnership, exist at a municipal school in Sao Paulo. This study used the method reference by exploration research through the case study. The study was done at the municipal elementary school, place that works with children with disabilities. The study used enrolled students on the model of Education of

\footnotetext{
* Professora Doutora em Educação Especial da Universidade Federal de São Carlos (UFSCar), São Carlos, São Paulo, Brasil.

** Professora Doutora em Educação Escolar da Universidade Federal de São Carlos (UFSCar), São Carlos, São Paulo, Brasil.
} 
Adults and Youth. The collection data occurred by semi- structure interview, focused on Expert Educational Service with people with disability. The result showed that the majority of the disabled students (EJA) had an intellectual disability. They also worked at on different places and did not show up at school (AEE). The teachers did not have trouble to working with those students. New study it is important to contemplate strength partnership between EJA and an Special Education.

Keywords: Special education. Young and adults education. Specialized educational services.

\section{Introdução}

A educação inclusiva caracteriza-se como um acesso à educação das pessoas historicamente excluídas por sua classe, etnia, gênero, idade ou deficiência. A proposta da inclusão escolar enfatiza, dentre outros aspectos, que os sistemas de ensino devem respeitar e atender às necessidades educacionais das pessoas com deficiência na classe regular. Para tanto, as escolas dispõem de vários serviços, recursos e estratégias, como: salas de recursos multifuncionais ou de apoio pedagógico, atendimento educacional especializado, acesso ao currículo etc.

Com base no exposto, o presente trabalho tem como foco o atendimento educacional especializado na Educação de Jovens e Adultos (EJA), a partir de um estudo de caso que está sendo realizado na rede municipal de ensino de uma cidade do interior do estado de São Paulo.

Os artigos 37 e 38 da Lei de Diretrizes e Bases (LDB) 9394/96 estabelecem que a EJA será destinada àqueles que não tiveram acesso ou continuidade de estudos no ensino fundamental e médio na idade adequada. Já o parecer CNE/CEB n. 11/2000, da Câmara de Educação Básica do Conselho Nacional de Educação, interpreta a norma do artigo 38 da LDB no sentido de que "os estudantes da EJA também devem se equiparar aos que sempre tiveram acesso à escolaridade e nela puderam permanecer". Trata-se, de acordo com o referido parecer, de um grupo heterogêneo de jovens e adultos.

Segundo Haddad e Di Pierro (2000), o desafio da expansão do atendimento na educação de jovens e adultos já não reside apenas na população que jamais foi à escola, mas se estende àquela que frequentou os bancos escolares e, no entanto, não obteve aprendizagens suficientes para participar plenamente da vida econômica, política e cultural do país e seguir aprendendo ao longo da vida.

Embora todos os grupos etários tenham, na conjuntura atual, necessidades de aprendizagem incrementadas, a maior parte das pessoas que busca no sistema edu- 
O aluno com deficiência na EJA: reflexões sobre o atendimento educacional especializado a partir do relato de uma professora da educação especial

cacional brasileiro oportunidades de estudos acelerados em horário noturno (as características da educação básica de jovens e adultos mais claramente percebidas) são adolescentes e jovens pobres que, após realizar uma trajetória escolar descontínua, marcada por insucessos e desistências, retornam à escola em busca de credenciais escolares e de espaços de aprendizagem, sociabilidade e expressão cultural. O perfil marcadamente juvenil que a educação escolar de adultos adquiriu no Brasil na última década deve-se à combinação de fatores ligados ao mercado de trabalho (exigência de certificação escolar) e ao sistema educativo (elevada defasagem na relação idade/série) (DI PIERRO, 2005, p. 1122)

Se por um lado observa-se um aumento expressivo no número de matrículas na educação de jovens e adultos; por outro, tem-se a descontinuidade de políticas e programas educacionais voltados para a modalidade de ensino em questão, distribuição de recursos financeiros aquém do desejável e, ainda, o pouco reconhecimento na discussão de questões específicas, como: necessidades do alunado da EJA, formação dos professores, currículo, procedimentos de ensino, dentre outros. Além disso, ainda são escassas as pesquisas brasileiras sobre a escolarização de alunos jovens e adultos com deficiência que contemplem efetivas ações educacionais à inclusão social e educacional deles; principalmente no contexto da modalidade escolar da Educação de Jovens e Adultos. Em relação a essa modalidade de ensino, conforme aponta Di Pierro (2005, p. 1121), "ainda mais notável é a escassez de conhecimento sobre as pessoas com necessidades especiais (...)".

No ano de 2009, houve 37.985 matrículas de alunos com deficiência (INEP/ MEC) na EJA, sendo 34.730 na EJA nível fundamental, e 3.255 no nível médio. Tal alunado corresponde a $0,81 \%$ do número de matrículas totais da Educação de Jovens e Adultos, com prevalência de matrículas no nível ensino fundamental. Vale ressaltar, ainda, que, quando comparados os censos escolares dos anos de 2008 e 2009, nota-se o aumento no número de matrículas de alunos com deficiência apenas nos anos finais do Ensino Fundamental, no Ensino Médio e na Educação de Jovens e Adultos.

As modalidades de educação de jovens e adultos e educação profissional apresentam-se como possibilidades de ampliação de oportunidades de escolarização, formação para a inserção no mundo do trabalho e efetiva participação social das pessoas com deficiência (BRASIL, 2008).

O documento proposto em 2009, durante a IV Conferência Internacional de Educação de Adultos, realizada no Brasil, sinaliza, dentre outros aspectos, que:

A educação inclusiva é fundamental para a realização do desenvolvimento humano, social e econômico. Pre- 


\begin{abstract}
parar todos os indivíduos para que desenvolvam seu potencial contribui significativamente para incentivá-los a conviver em harmonia e com dignidade. Não pode haver exclusão decorrente de idade, gênero, etnia, condição de imigrante, língua, religião, deficiência, ruralidade, identidade ou orientação sexual, pobreza, deslocamento ou encarceramento. É particularmente importante combater o efeito cumulativo de carências múltiplas. Devem ser tomadas medidas para aumentar a motivação e o acesso de todos. (UNESCO, p. 15)
\end{abstract}

Os documentos originados das Conferências Internacionais sobre Educação de Adultos, promovidas periodicamente desde 1949 pela Organização das Nações Unidas para a Educação, Ciência e Cultura (Unesco), reconhecem o caráter político da educação de jovens e adultos à medida que esta amplia a autonomia e potencializa a cidadania ativa dessas pessoas e grupos (DI PIERRO, 2010).

Seria interessante, portanto, que a pesquisa educacional pudesse mobilizar mais dados sobre como as práticas de educação de jovens e adultos de fato são desenvolvidas em situações diversas, isto é, questionar os currículos de formação presumidos feitos para esses educadores, saber quais objetos de ensino esses educadores selecionam, que concepções apresentam sobre o que se considera relevante ensinar e aprender e como elas orientam essas escolhas e a própria ação didática junto aos jovens e adultos (VÓVIO, 2010).

Tomemos como referência o Atendimento Educacional Especializado (AEE) na EJA. É preciso questionar: como o município vem estruturando as políticas de educação especial? Há alunos com deficiência matriculados na EJA? Os alunos com deficiência da EJA frequentam o AEE? Como estes atendimentos têm ocorrido?

A Política Nacional de Educação Especial na Perspectiva da Educação Inclusiva (2008) traz em seu conteúdo uma ampliação de conhecimentos, métodos e processos na escolarização das pessoas com deficiência, dentre estes o AEE, um serviço da educação especial que "[...] identifica, elabora e organiza recursos pedagógicos e de acessibilidade, que eliminem as barreiras para a plena participação dos alunos, considerando suas necessidades específicas" (SEESP/MEC, 2008, p. 16). A organização do atendimento deve prever a identificação, elaboração e organização de recursos de acessibilidade e pedagógicos ofertados em turno inverso ao da escolarização.

Segundo o Decreto n. 6.571, de 17 de setembro de 2008, considerase atendimento educacional especializado o conjunto de atividades, recursos de acessibilidade e pedagógicos organizados institucionalmente, prestado de forma a complementar ou suplementar à formação dos alunos no ensino regular, constituindo oferta obrigatória pelos sistemas de ensino. É realizado, preferencialmente, nas escolas comuns, em um espaço físico denominado Sala de Re- 
cursos Multifuncional; bem como em centro de atendimento educacional especializado da rede pública ou de instituição privada, compreendidas as comunitárias, confessionais ou filantrópicas sem fins lucrativos, com atuação exclusiva na educação especial, conveniadas com o poder executivo competente, podendo, ainda, ser ofertado em ambientes hospitalares e domiciliares (BRASIL, 2007; BRASIL, 2009).

As salas de recursos multifuncionais são ambientes dotados de equipamentos, mobiliários e materiais didáticos e pedagógicos para a oferta do atendimento educacional especializado. Embora as salas de recursos já existissem como espaço de realização do trabalho da educação especial em muitas redes de ensino no país, a versão atual, denominada multifuncional, foi concebida com um incremento nos elementos ligados à acessibilidade e tecnológicos (BRASIL, 2009).

Assim, considerando a proposta atual do Atendimento Educacional Especializado e a demanda de alunos com deficiência na Educação de Jovens e Adultos, o objetivo do estudo aqui apresentado, na etapa exploratória, foi verificar como se constitui a parceria entre o AEE e a EJA em uma escola da rede municipal de uma cidade da região central do estado de São Paulo.

\section{Desenvolvimento do estudo}

O presente estudo teve como referência metodológica a pesquisa exploratória, a partir da perspectiva do estudo de caso, ou seja, o estudo de uma realidade local e suas especificidades. A pesquisa exploratória visa proporcionar um maior conhecimento para o pesquisador acerca do assunto, a fim de que assim possa formular problemas mais precisos ou criar hipóteses que possam ser pesquisadas por estudos posteriores, além de proporcionar uma visão geral de determinado fato, do tipo aproximativo (GIL, 2008).

$\mathrm{Na}$ abordagem qualitativa, a pesquisa tem o ambiente natural como sua fonte direta de dados, os dados coletados são predominantemente descritivos, a preocupação com o processo é muito maior do que com o produto, o "significado" que as pessoas dão às coisas e à sua vida são focos de atenção especial pelo pesquisador, a análise dos dados tende a seguir um processo indutivo (BODGAN; BIKLEN, 1994; LÜDKE; ANDRÉ, 1996).

A pesquisa foi realizada na Secretaria Municipal de Educação de uma cidade do interior do estado de São Paulo, tendo como foco uma escola de ensino fundamental que possui alunos com deficiência matriculados na modalidade de Educação de Jovens e Adultos. No ano de 2010, a escola participante contava, no período noturno, com 179 alunos matriculados na modalidade EJA, sendo oito alunos com deficiência, com idade variando entre 16 a 25 anos, e a maioria com deficiência intelectual oriundos da APAE. Já no período da manhã, havia uma sala de EJA com 13 alunos, sendo dois alunos com deficiência intelectual, um com baixa visão, e um com condutas típicas. 
Foi realizada entrevista semiestruturada com a professora que atuava em serviço de AEE na referida escola.

\section{A Educação Especial no município pesquisado}

O município investigado localiza-se no centro geográfico do estado de São Paulo, com população estimada de aproximadamente 222.000 habitantes, sendo $96 \%$ pertencentes à área urbana (IBGE, 2010).

Dados do censo escolar de 2009 (MEC/INEP) revelam 39.171 matrículas de alunos na educação básica pública no município investigado, sendo 14.336 alunos matriculados na rede municipal de ensino, sendo189 matrículas de alunos com deficiência em classes comuns dos diferentes níveis de ensino. Com destaque para a Educação de Jovens e Adultos, os dados mostram que, em um total de 833 alunos matriculados no nível fundamental, 28 apresentam deficiência.

A Educação de Jovens e Adultos recebeu grande atenção por parte da Secretaria Municipal de Educação. As ações da Educação Especial inicialmente foram desenvolvidas pela equipe de apoio em Educação Especial, que desenvolviam estratégias juntamente com o professor responsável pelas salas. Nos anos de 2003 e 2004, este apoio foi estendido para uma professora com formação e experiência em Educação Especial para complementação da proposta e ampliação do número de atendimentos e acompanhamentos neste segmento.

Em 2005, o município estudado aderiu à proposta de atendimento educacional especializado em Sala de Recursos Multifuncionais. O projeto do MEC de implantação de Salas de Recursos Multifuncionais nas escolas municipais e estaduais tem como propósito apoiar os sistemas de ensino na oferta do atendimento educacional especializado, de forma complementar ou suplementar ao processo de escolarização, conforme previsto no inciso $\mathrm{V}$ do artigo $8^{\circ} \mathrm{da}$ Resolução CNE/CEB n. 2/2001.

As salas de recursos multifuncionais são espaços da escola onde se realiza $o$ atendimento educacional especializado para alunos com necessidades educacionais especiais, por meio do desenvolvimento de estratégias de aprendizagem, centradas em um novo fazer pedagógico que favoreça a construção de conhecimentos pelos alunos, subsidiando-os para que desenvolvam o currículo e participem da vida escolar (BRASIL, 2006).

Atualmente o município conta com 20 salas de recursos multifuncionais e com um quadro de profissionais da Educação Especial composto por 23 professores. 
O aluno com deficiência na EJA: reflexões sobre o atendimento educacional especializado a partir do relato de uma professora da educação especial

\section{Atendimento Educacional Especializado e a Educação de Jovens e Adultos: um retrato inicial do contexto investigado}

Os dados aqui apresentados referem-se ao relato de uma professora que atua na Educação Especial há 31 anos. Com formação em magistério, pedagogia e especialização em Educação Especial, a participante é responsável pelo Atendimento Educacional Especializado em uma escola de ensino fundamental da rede municipal de ensino que possui a modalidade Educação de Jovens e Adultos e também trabalha na Associação de Pais e Amigos do Excepcional (APAE) da cidade onde a pesquisa foi realizada.

Por meio de roteiro semiestruturado, na entrevista que teve como foco o Atendimento Educacional Especializado de alunos com deficiência da Educação de Jovens e Adultos, foram destacados os seguintes eixos temáticos: o percurso escolar do aluno com deficiência da EJA; expectativas da família sobre a EJA; trabalho da professora do AEE com o alunado com deficiência da EJA; parceria entre a professora do AEE e os professores da EJA.

\section{Percurso escolar do aluno com deficiência da EJA}

As salas de EJA, na escola em que a professora do AEE atua, funcionam no período do noturno, sendo que, em 2010, havia 179 alunos matriculados nesta modalidade, em que, segundo a professora do AEE, dez apresentavam deficiência intelectual. Há ainda, no período da manhã, uma sala da EJA com alunos com deficiência que, embora se localize em outro lugar próximo, pertence à escola. Em 2010, nesta sala, havia dois alunos com deficiência intelectual, um com baixa visão e um com condutas típicas.

A professora do AEE, ainda que faça referência aos alunos do período da manhã, enfatiza em sua fala os alunos com deficiência da EJA do noturno. Assim, as informações trazidas refletem a realidade destes alunos, que, de acordo com a professora, apresentam deficiência intelectual e são todos oriundos da APAE:

Sim, os que estão aqui vieram da APAE e às vezes surpreendem todo mundo, porque eles se saem melhores até do que aqueles que não têm problema, eles têm muita vontade, eles pegam, sabe, com garra, têm medo, tá, eles têm muito medo [...] os da APAE que vem pra cá, eles vem porque que estou aqui. (Professora AEE)

Interessante observar, na fala da professora, as expectativas trazidas por ela em relação aos alunos com deficiência. Estes alunos possuem um histórico de escolarização na instituição de educação especial, marcado pelo acompanhamento desta mesma professora, e que agora passa a configurar-se em outro contexto educacional. O histórico escolar marcado pela institucionalização resultou, segundo a professora, em poucas dificuldades no acompanhamento das aulas da EJA. No entanto, embora a escolarização na escola espe- 
cial tenha possibilitado à maioria destes alunos a alfabetização, não se tem ao certo outras habilidades alcançadas, uma vez que é muito forte na fala da professora a questão da alfabetização:

[...] a mãe quis tirar ele (da APAE), ele tem 16 anos, sabe, já é mocinho tal, então ele não quis mais ficar lá (na $A P A E)$, ele não estava pronto, então tem muitos casos assim, tá, que a mãe tira e vem procurar vaga. Aí é um problema sério, porque não está alfabetizado e está complicado, nós trabalhamos sete anos com ele lá, e nós não conseguimos alfabetizar, então é uma criança que não vai ser alfabetizada, você sabe que chegam a um limite que... a gente tenta, vai indo, mas é complicado. (Professora AEE)

Bueno (1997) indica que o processo de institucionalização da pessoa com deficiência contribui para a constituição tanto das concepções sociais acerca da condição quanto da identidade do próprio deficiente. $O$ autor nos mostra que a crença na dependência, na imaturidade, na improdutividade e na necessidade de uma educação segregada tem sustentação nos modos como foi se constituindo a educação institucionalizada da pessoa com deficiência.

\section{Expectativas da família sobre a EJA}

De alguma maneira, a família cria expectativas diante da escolarização de seus filhos com deficiência na EJA. Provavelmente, a inserção desses alunos em um novo ambiente escolar seja também para a família motivos de medos, inseguranças; por outro lado, sinaliza a motivação na continuidade dos estudos de seus filhos. As experiências e vivências que estes familiares tiveram com a questão da deficiência durante a história de suas vidas e de seus filhos, de certo modo influenciam suas atitudes.

Sobre o futuro escolar do filho com deficiência intelectual, as expectativas apresentadas pelos pais parecem ser as mesmas que eles teriam para qualquer outro filho, e não poderia ser diferente, pois, em geral, os pais almejam que os filhos tenham sucesso e, de certa forma, se o filho fracassa, a família tende a se responsabilizar por isso (LIMA, 2009).

[...] é uma ou outra mãe que tem muita preocupação. $\dot{A}$ noite, por exemplo, eu tenho uma que a mãe vem junto com a filha, tá, ela saiu da APAE, veio pra cá, e a mãe está junto com ela, pra ela não desistir (...) você vê....a mãe se propôs a estudar pra poder vir com a filha. (professora AEE)

Assim, ainda é nítida a preocupação desses familiares com a questão da alfabetização. Segundo Vóvio (2010, p. 69), os processos de alfabetização e escolarização trazem consequências para os sujeitos que deles encontram-se 
O aluno com deficiência na EJA: reflexões sobre o atendimento educacional especializado a partir do relato de uma professora da educação especial

excluídos, "principalmente, porque os colocam em desvantagem no jogo social e pelo estigma atribuído socialmente aos que não sabem ler e escrever ou não se escolarizam".

Considerando que o movimento da Educação para Todos/as e da Educação Inclusiva promoveu a inclusão de crianças, jovens e adultos de grupos vulneráveis nas escolas, agora é necessária uma ruptura paradigmática com relação à compreensão das comunidades escolares sobre o valor e o papel dos pais/mães e outros familiares e responsáveis no processo educacional dos fiIhos/as (FERREIRA, 2009, p. 117).

[...] outra mãe, também, de um rapaz, também está sempre procurando a gente, só que elas são muito ansiosas, tá, então vamos supor, "Quando que o meu filho vai ler?", vamos supor aquele que não lê, é meio complicado, você explica pra ela; outra coisa, tem um aluno aqui que ele lê, só que ele não está preparado pra quinta série, e a mãe quer que coloque na quinta série, mas ele não está preparado, então você tem esses conflitos, a ansiedade das mães. (professora AEE)

Com isso, outras questões significativas, como o desenvolvimento e a aprendizagem de habilidades importantes para a vida em sociedade, para o trabalho e autonomia da pessoa com deficiência intelectual, acabam em segundo plano; não se levando em conta as limitações cognitivas decorrentes da deficiência. O relato evidencia também a visão infantilizada da professora da aluna. Estudos realizados por Glat (1989), Ferreira (1994), entre outros, apontam para a intensa infantilização da pessoa com deficiência intelectual no âmbito institucional.

Trabalho da professora do AEE junto ao alunado com deficiência e professores da EJA

Em relação ao trabalho da professora junto aos alunos da EJA, a fala da participante sinaliza pontos importantes a respeito do AEE,

[...] qualquer problema, eles me procuram. Então é assim, eu não posso tirar da sala de aula pra atender, eles querem o quê? que você atenda esses alunos em horários contrários, eles trabalham já, eles não podem vim aqui ter aula, um só, que eu chego às seis, que eu atendo ele das seis às sete, ele não está alfabetizado ainda (Professora AEE)

Nesse relato, evidencia-se a preocupação da professora em encontrar horários para dar suporte na aprendizagem da leitura e escrita desses alunos, ela deixa clara sua preocupação na alfabetização. Tal realidade deve ser reforçada pelo fato de que inexiste a oferta de serviço Atendimento Educacional 
Especializado no turno da noite das escolas regulares, e além disso, na Resolução n. 04/2009 do CNE, não há nenhum artigo ou parágrafo que trate de AEE para estudantes com deficiência nas turmas de EJA.

Não podemos esquecer que, de acordo com a proposta, o Atendimento Educacional Especializado decorre de uma nova concepção da Educação Especial, e é uma das condições para o sucesso da inclusão escolar dos alunos com deficiência. Esse atendimento deve favorecer diferentes aprendizagens dos conteúdos curriculares do ensino comum e é necessário para que possam ser ultrapassadas as barreiras impostas pela deficiência.

Agora os que estão alfabetizados [...] não ocorreu nada assim, que eu precisei preparar material, pois que eles conseguem acompanhar, diferente de outros tipos de necessidades especiais, que você precisa fazer ajudar, [...] nunca tivemos problema de ter que preparar material não, eles conseguem acompanhar o conteúdo da sala. (Professora AEE)

Observa-se que a caracterização do lócus preferencial e o papel do AEE se tornaram restritos, ou seja, segundo a legislação atual, Decreto n. 6.571, de 17 de setembro de 2008, as salas de recursos multifuncionais têm um papel de caráter mais instrumental: "são ambientes dotados de equipamentos, mobiliários e materiais didáticos e pedagógicos para a oferta do atendimento educacional especializado". Contudo, a Política de Educação Especial na perspectiva da Educação Inclusiva (2008, p.15) propõe que, além do atendimento às necessidades específicas, as atividades desenvolvidas no AEE complementem e suplementem a formação dos alunos com vistas à autonomia e independência na escola e fora dela.

Considerando o contexto da Educação de Jovens e Adultos, Vóvio (2010, p. 65) comenta que:

Os conteúdos e propostas pedagógicas muitas vezes reproduzem, de modo aligeirado, currículos e programas da educação regular, consideram apenas as culturas tomadas como legítimas e apagam aquelas dos grupos a que se dirigem. Além disso, nem sempre possuem em seu horizonte as necessidades de aprendizagem e a bagagem experiencial dos diretamente envolvidos nessas ações educativas.

Em outras palavras, significa dizer que os alunos podem trazer para os atendimentos os conteúdos advindos da sua própria experiência, segundo seus desejos, necessidades e capacidades. No caso, especificamente da EJA, os professores poderiam focalizar uma preparação para o trabalho e melhor autonomia na vida social. 
O aluno com deficiência na EJA: reflexões sobre o atendimento educacional especializado a partir do relato de uma professora da educação especial

No caso específico dos alunos com deficiência intelectual, uma das inquietações do contexto atual da educação especial refere-se à certificação de conclusão de escolarização de alunos com deficiência intelectual; isto é, em fazer cumprir a "terminalidade específica" prevista em lei (LDB n. 9394/96), focada nas competências desenvolvidas pelo educando, bem como o encaminhamento devido desses alunos para a educação de jovens e adultos e para a educação profissional. Na realidade, o que se observa é a indefinição relacionada ao certificado da escolaridade, ou seja, muitos não estão sabendo qual caminho seguir, quais contribuições funcionais a escolarização deveria oferecer aos alunos com deficiência intelectual.

Assim, partindo do pressuposto de que a Educação de Jovens e Adultos seria um espaço de emancipação e formação para a cidadania e vida adulta, neste caso, dos alunos com deficiência intelectual; cabe questionar até que ponto estes "novos" espaços não se configuram nos moldes das escolas e/ou classes especiais, onde muitos desses alunos conviveram por longos anos.

\section{Considerações finais}

Apesar de a legislação brasileira reconhecer a EJA como modalidade de ensino também para as pessoas com deficiência como um direito, percebese que o acesso a serviços e recursos, ainda é frequentemente negado.

O Decreto n.6.571, de 17/09/2008, vem regulamentar as novas diretrizes de Educação Especial na perspectiva da Educação Inclusiva (2008) que concebe o Atendimento Educacional Especializado como o conjunto de atividades, recursos de acessibilidade e pedagógicos. Contudo, ao analisar elementos presentes na fala da professora do AEE do presente estudo, verifica-se que os professores da EJA não precisavam de auxílio, pois não eram realizadas adaptações nos materiais para trabalhar com os alunos.

Os professores das escolas comuns deveriam articular-se com os professores da educação especial, no sentido de obter o suporte necessário para garantir que os alunos com deficiência consigam aprender os conteúdos do currículo e atividades que garantam a formação dos alunos com vistas à autonomia e independência na escola e fora dela.

Torna-se importante questionar porque essas atividades não estão sendo realizadas na educação de jovens e adultos com deficiência. Será que esse atendimento foi pensado para o grupo desses alunos jovens e adultos que trabalham? Fazem-se necessários, portanto, novos estudos que contemplem ações necessárias à efetiva parceria entre a EJA e a Educação Especial. 


\section{Referências}

BUENO, J. G. A produção social da identidade do anormal. In: FREITAS, M. C. (Org.). História social da infância no Brasil. São Paulo: Cortez, 1997. p. 159181.

BRASIL. Ministério da Educação. Secretaria de Educação Especial. Diretrizes Operacionais da Educação Especial para o Atendimento Educacional Especializado na Educação Básica. Brasília: MEC/SEESP, 2009.

. INEP. Censo Escolar, 2009. Disponível em: <http://www.inep.gov.br/ censo/escolar/DOU_final_2008.htm>. Acesso em: 20 mar. 2009.

BRASIL. INEP. Censo Escolar, 2008. Disponível em: <http:// www.portaldoprofessor.inep.gov.br/imprensa/noticias/censo/escolar/ news09_02_imp.>. Acesso em: 20 mar. 2009.

. Ministério da Educação. Secretaria de Educação Especial. Política Nacional de Educação Especial na Perspectiva da Educação Inclusiva. Inclusão: revista da educação especial, v. 4, n. 1, jan./jun. 2008. Brasília: MEC/ SEESP, 2008.

Ministério da Educação. Decreto n. 6.571, de 17 de setembro de 2008. Disponível em: <http://www.planalto.gov.br/ccivil_03/_Ato2007-2010/2008/ Decreto/D6571.htm>. Acesso em: 02 mar. 2011.

. Lei no 9.394 de 20 de dezembro de 1996. Estabelece as diretrizes e bases da educação nacional.

BATISTA, C. A. M.; MANTOAN, M. T. E. Educação Inclusiva: atendimento educacional especializado para a deficiência mental. Brasília: MEC/SEESP, 2005.

BOGDAN, R.; BIKLEN, S. Investigação qualitativa em educação: uma introdução á teoria e aos métodos. Porto: Porto, 1994.

DI PIERRO, M. C. Educação de Jovens e Adultos. In: OLIVEIRA, D.; DUARTE, A. M. C.; VIEIRA, L. M. F. Dicionário de trabalho, profissão e condição docente. Belo Horizonte: Faculdade de Educação; Universidade Federal de Minas Gerais, 2010. p. 8.

DI PIERRO, M. C. Notas sobre a redefinição da identidade e das políticas públicas de educação de jovens e adultos no Brasil. Educação e Sociedade, v. 26, n. 92, p. 1115-1139, out. 2005. ISSN 0101-7330.

FERREIRA, A. B. de H. Dicionário Aurélio básico da língua portuguesa. Rio de Janeiro: Nova Fronteira, 2010.

FERREIRA, W. B. EJA \& deficiência: estudo da oferta da modalidade EJA para estudantes com deficiência. In: PAIVA, J.; BARBOSA, M.J.; FERREIRA, W. B. Educação de Jovens e adultos: o que dizem as pesquisas. Recife: Gráfica J. Luiz Vasconcelos, 2009. p. 75-128. 
O aluno com deficiência na EJA: reflexões sobre o atendimento educacional especializado a partir do relato de uma professora da educação especial

FERREIRA, M.C.C. A prática educativa e a concepção de desenvolvimento psicológico de alunos com deficiência mental. 1994. 160 f. Tese (Doutorado em Educação)-Programa de Pós-Graduação em Educação, Faculdade de Educação, Universidade Estadual de Campinas, Campinas, 1994.

GIL, A. C. Como elaborar projetos de pesquisa. 4. ed. São Paulo: Atlas, 2008.

GLAT, R. Somos iguais a vocês: depoimentos de mulheres com deficiência mental. Rio de Janeiro: Agir, 1989.

HADDAD, S.; DI PIERRO, M. C. Aprendizagem de jovens e adultos: avaliação da década da educação para todos. São Paulo Perspec. [online], v.14, n.1, p. 29-40, 2000.

LUDKE, M.; ANDRÉ, M. E. D. A pesquisa em educação: abordagens qualitativas: São Paulo: EPU, 1996.

LIMA, S. R. Escolarização da pessoa com deficiência intelectual: terminalidade específica e expectativas familiares. 2009, $179 \mathrm{f}$. Tese (Doutorado em Educação Especial)-Programa de Pós-Graduação em Educação EspecialUniversidade Federal de São Carlos, São Carlos, 2009.

MARINS, S. C. F.; PALHARES, M. C. Educação inclusiva: relato de uma experiência a partir da visão dos gestores municipais. Cadernos de Terapia Ocupacional da UFSCAR, 2007, p. 69-89.

SILVA. A. P. R. da; Junior A. F. A política educacional do primeiro governo petista de São Carlos-SP (2001-2004). Ensaio: aval. políticas. públicas. Educação, Rio de Janeiro, v. 18, n. 68, p. 549-588, jul./set. 2010.

VÓVIO, C. L. Formação de educadores de jovens e adultos: a apropriação de saberes e de práticas conectadas a docência. In: DALBEN, A. et al. (Org.).Convergências e tensões no campo da formação do trabalho docente. Belo Horizonte: Autêntica, 2010. p. 60-77.

\section{Correspondência}

Juliane Aparecida Corrêa Perez Campos - Rua Amaldo Victaliano, 1450, apto. 144. Jardim Iguatemi. Cep.: 14091-220. Ribeirão Preto, São Paulo, Brasil.

E-mail: jappcampos@gmail.com

Recebido 25 de abril de 2011

Aprovado em 18 de maio de 2011 